\title{
Actividad antimicrobiana de bacterias endófitas aisladas de orégano serrano (Lippia origanoides) contra Burkholderia glumae y Colletotrichum gloeosporioides
}

\section{Antimicrobial activity of endophytic bacteria isolated from serrano oregano (Lippia origanoides) against Burkholderia glumae and Colletotrichum gloeosporioides}

\author{
Arrieta D, Lorena ${ }^{1}$ Biol, Chamorro A, Leonardo ${ }^{1 *}$ M.Sc, Montes V, Donicer ${ }^{2}$ Ph.D.
}

${ }^{1}$ Universidad de Sucre. Facultad de Ciencias Agropecuarias. Grupo Bioprospección Agropecuaria. Sincelejo, Sucre.

2 Universidad de Sucre. Facultad de Ciencias Agropecuarias. Grupo de Reproducción y Mejoramiento Genético Animal. Sincelejo, Sucre.

Keywords:

Antimicrobial activity; endophytic bacteria; secondary metabolites.

\section{Palabras Clave:}

Actividad antimicrobiana; bacterias endófitas; metabolitos secundarios.
INFORMACIÓN

Recibido: 21-06-2016;

Aceptado: 20-10-2016.

Correspondencia autor:

mscbiologia@gmail.com

\section{Abstract}

The objective of this study was to determinate endophytic diversity associated to Lippia origanoides from Sabana subregion in the Department of Sucre, Colombia and evaluate their antimicrobial activity against Colletotrichum gloeosporioides and Burkholderia glumae. Tissue surface disinfection technique was used and isolation was performed on $R_{2} A$ agar culture medium. Population density (CFU / g tissue) was estimated by direct counting of colonies on plate. Statistics significances between population density in relation to tissues and site, was made by multivariate analysis and multiple range test (Tukey). Endophytic bacteria that showed inhibition of pathogenic microorganisms were subjected to an extraction of secondary metabolites. The antimicrobial, antifungal and secondary metabolites test were carried out by testing confrontation and qualitative estimation. The results show that there is a population density of endophytic bacteria associated with oregano plants and abundance is related to tissues. None of the morphotypes showed antimicrobial activity for B. glumae. One morphotypes had antifungal activity against $C$. gloeosporioides and metabolites extraction was performed for antifungal activity from cell suspensions.

\section{Resumen}

El objetivo de éste estudio fue determinar la diversidad de bacterias endófitas asociadas a la especie vegetal Lippia origanoides de la subregión sabanas en el Departamento de Sucre, Colombia y evaluar su actividad antimicrobiana contra Colletotrichum gloeosporioides y Burkholderia glumae. Se utilizó la técnica de desinfección superficial de tejidos y el aislamiento se realizó en medio de cultivo agar $R_{2} A$. La densidad poblacional (UFC/g de tejido) se estimó por conteo directo de colonias en placa. Las significancias estadísticas entre densidad poblacional, con relación a tejidos y sitio, se realizó mediante análisis multifactorial y prueba múltiple de rango (Tukey). Las bacterias endófitas que presentaron inhibición contra los microorganismos patógenos fueron sometidas a un proceso de extracción de metabolitos secundarios. La prueba antimicrobiana, antifúngica y de metabolitos secundarios se llevaron a cabo mediante ensayos de confrontación y estimación cualitativa. Los resultados muestran que existe una densidad poblacional de bacterias endófitas asociadas a plantas de orégano serrano y la abundancia está relacionada con el tejido. Ninguno de los morfotipos presentó actividad antimicrobiana para B. glumae. Uno de los morfotipos tuvo actividad antifúngica frente a $C$. gloeosporioides y se le realizó extracción de metabolitos para determinar la actividad antifúngica a partir de suspensiones celulares. 


\section{INTRODUCCIÓN}

El Departamento de Sucre históricamente ha tenido una actividad económica basada en la producción agropecuaria, con poco valor agregado y orientada al mercado interno. La baja utilización de la capacidad de producción agrícola obedece a los bajos niveles de inversión y tecnología (riego, drenaje, transferencia tecnológica e investigación) que se reflejan en los bajos rendimientos por hectáreas. Además, al mal estado de las vías de comunicación que retrasan el envío de los productos a los centros de consumo, la poca agroindustrialización que le adicione valor agregado a los productos agropecuarios, y los ineficientes canales de comercialización, entre otros. A lo anterior se suman los factores climáticos adversos y la inseguridad.

Los factores fisiográficos, edáficos y las acciones antrópicas degenerativas del medio natural, que eliminan la cobertura arbórea y degradan el suelo, producen condiciones de acidez en el suelo con predominio de las sequías estacionales y de árboles de hoja poco durables. Un estudio en la subregión Sabanas Sucre-Colombia, determinó que la sobreexplotación y las prácticas de monocultivos por más de tres décadas, han deteriorado la capa vegetal y llevado a la degradación de algunas áreas. Estudios realizados por AGUILERA, 2005, propone tres sistemas de reforestación: el primero, consiste en la siembra de arbustos en la pastura; el segundo, la combinación de arbustos y especies arbóreas y otras especies leguminosas y que sean fijadoras de nitrógeno; el tercero, es similar al anterior pero con árboles maderables.

Dentro de los cultivos tradicionales colombianos, el ñame (Dioscoreae), tiene una relevada importancia socioeconómica en la región Caribe, especialmente en Sucre y hace parte de la dieta alimenticia de la población. El cultivo es manejado en forma artesanal con utilización de mano de obra familiar constituyéndose en un producto de economía campesina para el departamento. El ñame se cultiva en pequeñas áreas y es poca o ninguna la injerencia institucional en lo que a investigación y asistencia técnica se refiere atribuyéndosele en parte a estos aspectos la baja productividad y rentabilidad del cultivo. Como limitantes importantes de la producción se tiene la enfermedad llamada antracnosis causada por el hongo Colletotrichum gloeosporiodes, la cual afecta a los genotipos comerciales de la especie $D$. alata (CAMPO, 2011). Los intentos para dar solución al problema de antracnosis han tenido diferentes alternativas. Las plantas nativas siguen siendo en la actualidad una alternativa valiosa para el tratamiento de diversas enfermedades en cultivos a nivel mundial. Es importante la búsqueda de nuevos agentes antifúngicos que ayuden a controlar el incremento de cepas patógenas de Colletotrichum de elevada resistencia a los fungicidas.

El arroz es el cereal que más se consume en el mundo después del trigo. Brinda a más de la mitad de la población el $50 \%$ de las calorías necesarias en su alimentación. En Colombia, el arroz es uno de los cultivos de ciclo corto más importantes. Sucre es el departamento con mayor producción de arroz tradicional con 10.262 toneladas, seguido de Córdoba y Bolívar. El segundo semestre del año, para el arroz tradicional, reporta la mayor producción del año con un rendimiento de 2,7 toneladas por hectárea (DANE, 2013). Las enfermedades constituyen un limitante en el cultivo de arroz y aún más relevante es el incremento de la intensidad de las causadas por bacterias que hasta hace un tiempo presentaban baja importancia (PÉREZ \& CHAMORRO, 2011). Una de ellas es el añublo bacterial de la panícula del arroz causada por la bacteria Burkholderia glumae la cual tiene un gran impacto en el rendimiento del cultivo debido a las pérdidas económicas que produce.

Con base en lo planteado anteriormente, el objetivo de esta investigación fue, evaluar la actividad antimicrobiana de bacterias endófitas aisladas de $L$. origanoides en la subregión Sabanas del departamento de Sucre (Colombia) contra Burkholderia glumae y Colletotrichum gloeosporioides.

\section{MATERIALES Y MÉTODOS}

El material vegetal se recolectó en cuatro localidades de la subregión Sabanas en el departamento de Sucre (Colombia). Se tomaron 10 plantas completas de orégano serrano (Lippia origanoides) teniendo en cuenta su estado fitosanitario, se rotularon y se trasladaron al laboratorio de investigaciones microbiológicas de la Universidad de Sucre para su respectivo análisis microbiológico.

Aislamiento de endófitas. Las muestras de los tejidos de orégano fueron sometidas a un proceso de desinfección descrito por PÉREZ et al., (2010). Cada muestra se maceró hasta obtener una mezcla homogénea y se mantuvieron en agitación durante 24 horas. Se realizaron diluciones seriadas, éstas fueron sembradas por técnica de difusión sobre superficie de agar $\mathrm{R}_{2} \mathrm{~A}$ e incubadas a $28^{\circ} \mathrm{C}$ por 72 horas. La densidad poblacional de bacterias endófitas por tejido (UFC/g de tejido), se estimó por conteo directo de colonias en placas. Las colonias se observaron y se seleccionaron en cuanto a forma, tamaño, color y aspecto de la superficie. Los morfotipos seleccionados se purificaron y se mantuvieron en agar $R_{2} A$ para su evaluación in vitro. 
Prueba de actividad antifúngica. Todos los morfotipos fueron evaluados en cuanto a su capacidad para inhibir el crecimiento micelial del hongo fitopatógeno Colletotrichum gloeosporioides, mediante ensayos de confrontación y estimación cualitativa. Con tres días de anterioridad se inoculó micelio de C. gloeosporioides de siete días de edad, se depositó en el centro de una caja Petri con medio PDA en ambiente aséptico. Al día siguiente, en cajas con medio PDA- $R_{2} A$ se inocularon los aislados bacterianos con una línea al extremo de la caja, dos días después se utilizó el método de siembra directa con crecimiento puro de los aislados C. gloeosporioides, se cortaron con sacabocados a partir de la periferia de una colonia de 10 días de edad, cada aislado de aproximadamente $6 \mathrm{~mm}$ de diámetro de área de crecimiento (PÉREZ et al., 2011), se inoculo sobre la superficie del medio. Las cajas se incubaron a $30^{\circ} \mathrm{C}$ por 7 días. Se utilizó un testigo absoluto para compararlo con los resultados y se consideró como potenciales antagonistas aquéllos aislamientos que causaron algún grado de inhibición del crecimiento micelial de C. gloeosporioides, alrededor de la zona de crecimiento de las colonias bacterianas.

Prueba de actividad antibacteriana. La evaluación de la actividad antibacteriana de bacterias endófitas contra $B$. glumae consistió en realizar siembra en superficie sobre agar King B. La preparación de las bacterias endófitas empleadas en el presente estudio consistió en tomar 1 a 3 colonias bien aisladas con el asa estéril transfiriéndolas a un frasco con $5 \mathrm{ml}$ de agua peptonada estéril y se llevó a agitación constante por 24 horas hasta alcanzar la turbidez. Discos estériles de papel fueron sumergidos en las suspensiones celulares y se depositaron sobre la superficie del medio de cultivo inoculado previamente con B. glumae. Las placas se incubaron a $28^{\circ} \mathrm{C}$ por 24 horas (CUELLAR \& HUSSEIN, 2009). El antibiótico ácido oxolínico $10 \mu \mathrm{g}$ fue utilizado como control positivo. Los ensayos se realizaron por triplicado y la evaluación se realizó por las zonas de inhibición de crecimiento alrededor de los discos. La eficiencia de la actividad antibacteriana de las bacterias endófitas contra $B$. glumae se realizó por comparación con los resultados obtenidos con el control positivo (ROJAS et al., 2012).

Obtención de metabolitos secundarios. Se inoculó una colonia de bacterias en $200 \mathrm{ml}$ de Medio $\mathrm{N}^{\circ} 3$ compuesto por $10 \mathrm{~g}$ de peptona, $10 \mathrm{~g}$ de D-glucosa, $1 \mathrm{~g}$ de $\mathrm{KH}_{2} \mathrm{PO}_{4}$ y $0.5 \mathrm{~g}$ de $\mathrm{MgSO}_{4}+7 \mathrm{H}_{2} \mathrm{O} \mathrm{pH} 6.8$ (CHO et al., 2007) durante 6 días a $150 \mathrm{rpm}$. Se centrifugó el medio a 10000 rpm por 10 min a $4^{\circ} \mathrm{C}$, el sobrenadante se pasó por un filtro de membrana de $0.2 \mu \mathrm{m}$, se guardó el extracto en frascos estériles y se almacenó en frío hasta realizar las pruebas. El resultado se interpretó como porcentaje de índice antifúngico: \% I.A = [1-(Da/ Db) $]$ x 100, donde $\mathrm{Da}$ corresponde al crecimiento de cada tratamiento y $\mathrm{Db}$ al crecimiento del testigo absoluto (ZHANYONG et al., 2008).
Análisis estadístico. Las diferencias entre la densidad poblacional (UFC/g de tejido) de bacterias endófitas en función al tipo de tejido y el sitio de muestreo fue analizada por ANOVA multifactorial. Para establecer diferencias por separado entre comunidades de bacterias endófitas entre tipo de tejido y sitio se utilizó la prueba múltiple de rango (Tukey).

\section{RESULTADOS Y DISCUSIÓN}

Un total de 56 morfotipos de bacterias fueron aislados de los diferentes tejidos (raíz, tallo y hojas) de las plantas L. origanoides (Figura. 1). El número de colonias varió significativamente para tipo de tejido analizado y sitio de muestreo. El análisis de varianza multifactorial (UFC/ g de tejido) de bacterias endófitas mostró diferencias significativas tanto para tejido como sitio de muestreo (Tabla 1).

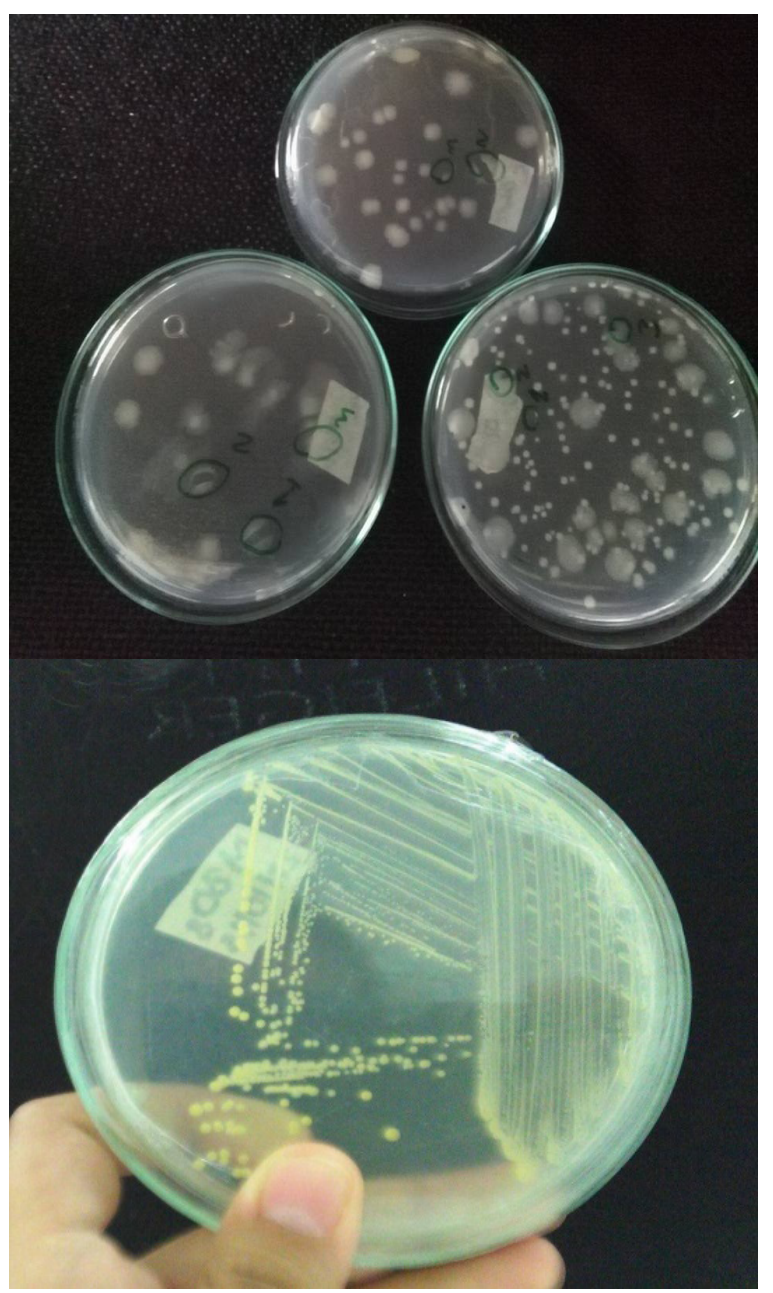

Figura. 1. Diversidad de bacterias endófitas aisladas de orégano. A) Colonias de aislados endófitos de tejidos de la planta (raíz, tallo, hojas). B) Morfotipos seleccionados y purificados teniendo en cuenta forma, tamaño y color 
Tabla 1. Anova multifactorial de UFC/g de tejido de bacterias endófitas en tejidos

$\begin{array}{cccccc}\text { Fuente } & \text { G. I } & \text { S. C } & \text { M. C } & \text { Razón F } & \text { Valor P } \\ \text { TEJIDO } & 2 & 28.126 & 14.063 & 39.172 & 2.77 \mathrm{e}-08 \text { *** } \\ \text { SITIO } & 3 & 4.040 & 1.347 & 3.751 & 0.0243^{*} \\ \text { TEJIDO/SITIO } & 6 & 7.472 & 1.245 & 3.469 & 0.0130 \text { * } \\ \text { Residuos } & 24 & 8.616 & 0.359 & & \end{array}$

${ }^{* * *}$ Altamente significativo a intervalos de confianza del $95.0 \%$.

La prueba múltiple de rango (Tukey) para comunidades de bacterias endófitas (UFC/g de tejido) mostró una diferencia significativa en cuanto a tipo de tejido mostrando mayor presencia de colonias en raíces $4.1 \times 10^{8}$, en tallos $2.5 \times 10^{8}$ y en menor cantidad en hojas $2.3 \times 10^{6}$ respectivamente (Figura. 2 ).

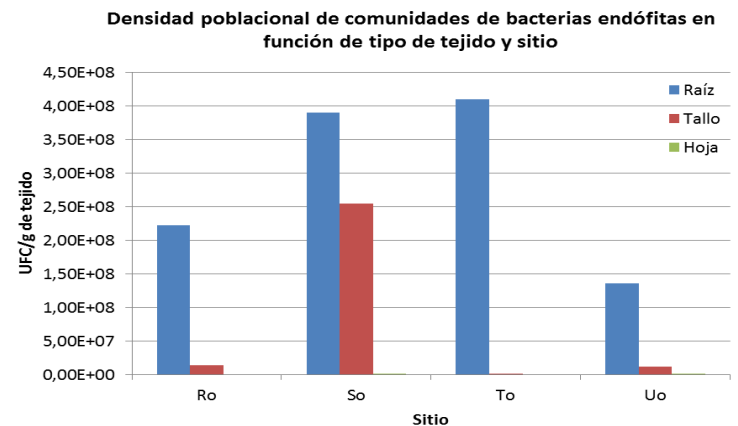

Figura. 2. Densidad poblacional promedia de bacterias endófitas asociadas a tejidos de Orégano (Lippia origanoides). Ro: Guácimo, So: Galeras, To: Corozal, Uo: Sincé. Sotios de muestreo en la subregión Sabanas, Sucre.

Las plantas son consideradas microecosistemas complejos en los cuales diferentes nichos pueden ser explorados por una extensa variedad de microorganismos, incluyendo bacterias endófitas. Las bacterias endófitas están presentes en tejidos vegetales, no causan daño a la planta o producen estructuras externas que emergen de dichos tejidos (AZEVEDO, 2007).

Los estudios de interacciones planta/microorganismos y la función de estos microorganismos en las plantas han indicado su utilidad para un gran número de aplicaciones, tales como el control biológico de diferentes enfermedades, promoción del crecimiento vegetal y biorremediación de ambientes contaminados (SOUZA, 2014). La eficacia de los endófitos como agentes de control biológico depende de muchos factores: la especificidad del huésped, la dinámica de la población y el patrón de colonización, la capacidad de moverse dentro de los tejidos del huésped, y la capacidad de inducir resistencia sistémica (MELNICK et al., 2008).
Actualmente, el control de agentes bióticos que afectan el rendimiento de cultivos tales como enfermedades y plagas se realiza con la aplicación de pesticidas sintéticos que degradan el ambiente, causan toxicidad en humanos y animales. Así mismo, pueden ser letales para los microorganismos benéficos de la rizósfera e insectos del suelo (KIM \& CHUNG, 2004). Por las razones mencionadas y por el surgimiento de fitopatógenos resistentes a los pesticidas, es necesario implementar alternativas que representen menor peligro para organismos que no son blanco y se sugiere a los microorganismos como método de control biológico.

De los morfotipos seleccionados, ninguno mostró actividad antibacteriana contra $B$. glumae causante del añublo bacterial en arroz, sin embargo uno de ellos mostró actividad antifúngica contra el hongo fitopatógeno C. gloeosporioides causante de la antracnosis en cultivos de ñame (Figura. 3). Asimismo, se obtuvo metabolitos secundarios a partir de la suspensión bacteriana de dicho morfotipo y éste presentó actividad antifungica positiva.

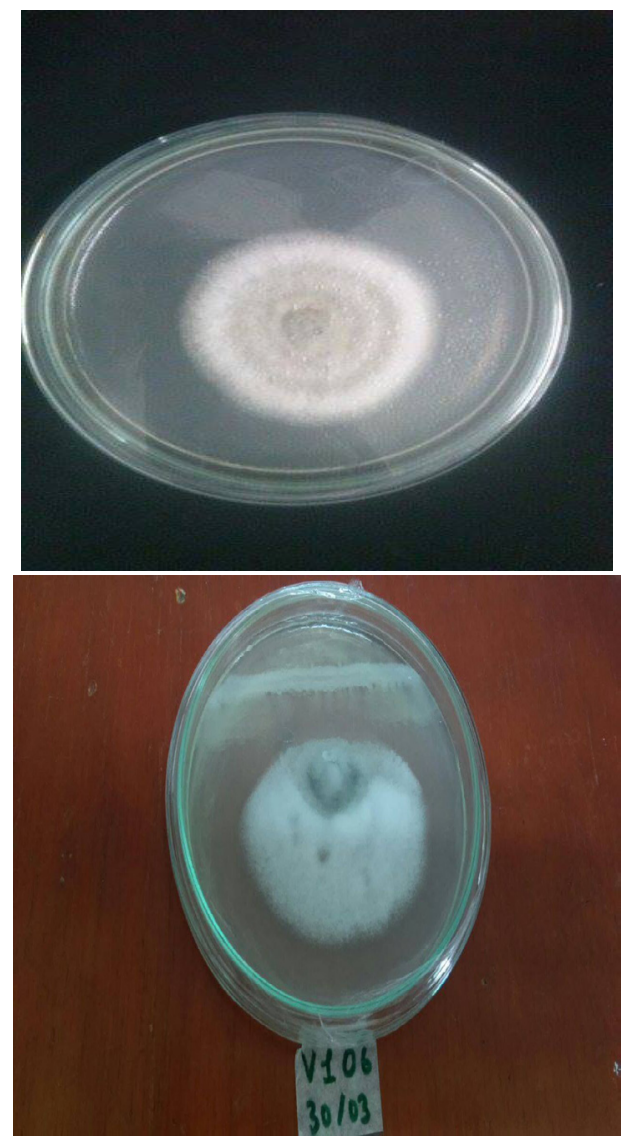

Figura. 3. Actividad antifúngica de bacterias endófitas de orégano. A) Control. B) Inhibición del crecimiento de Colletotrichum gloeosporioides por el efecto antagónico de los aislados endófitos. 
La actividad antifungica de los metabolitos secundarios obtenidos se evaluó a una concentración de 30 y $45 \%$ (Figura. 4) con un índice de inhibición de 2 y 14\% respectivamente, razón por la cual se sugiere aumentar dicha concentración en futuras investigaciones para mejores resultados. La exploración de la diversidad microbiana y la cantidad de metabolitos secundarios producidos por bacterias ha llevado a considerarlos como una fuente importante de productos naturales con propiedades biológicas como antibacterianos, antifúngicos, antitumorales, hipocolesterolémicos, inmunosupresores, antiparasitarios, herbicidas e insecticidas, entre otros. Los metabolitos secundarios son definidos como sustancias de bajo peso molecular, que no se producen en la vía metabólica primaria y que no juegan un papel fundamental en las funciones primarias o de crecimiento. A diferencia de los metabolitos primarios, los cuales son comunes en todos los sistemas biológicos, los metabolitos secundarios, son química y taxonómicamente diversos, presentando funciones desconocidas (SIERRA et al., 2012).

\section{CONCLUSIÓN}

Las bacterias endófitas representan una gran utilidad para diversas aplicaciones, tales como el control biológico de diferentes enfermedades, promoción del crecimiento vegetal y biorremediación de ambientes contaminados. La densidad poblacional de los endófitos varía significativamente con respecto a tipo de tejido y sitio de muestreo. Los morfotipos evaluados presentaron actividad antifúngica por medio de ensayos de confrontación y metabolitos secundarios bacterianos.

\section{Agradecimientos.}

Los autores y la Universidad de Sucre, expresan sus agradecimientos al Fondo Nacional de Ciencias, Tecnología e Innovación (CTe I) del Sistema general de regalías- SGR, por el otorgamiento de recursos económicos con destinos al departamento de Sucre para la ejecución de las actividades de Ciencia, Tecnología e Innovación en el marco del proyecto denominado "Implementación de un programa para el desarrollo de productos biotecnológicos para el sector agrícola en el Dpto de Sucre", CODIGO BPIN 2013000100022 y al Departamento de Sucre por todo el apoyo brindado.

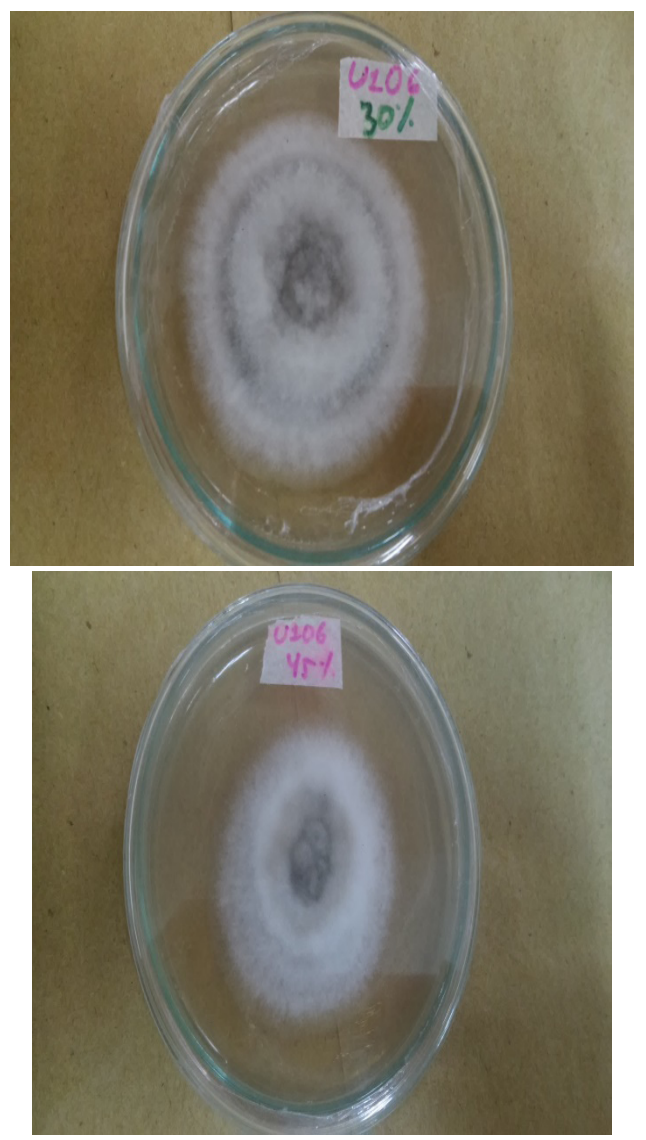

Figura. 4. Acción antifúngica contra C. gloeosporioides de metabolitos secundarios extraídos de suspensiones bacterianas a partir de endófitos.

\section{REFERENCIAS}

AGUILERA, M. 2005. La economía del departamento de Sucre: ganadería y sector público. [Internet] Disponible en: <<http://www.banrep.gov.co/docum/Lectura finanzas/pdf/DTSER-63-VE.pdf>>. Fecha de acceso: 18/03/2016. AZEVEDO, J.; ARAUJO, W. 2007. Diversity and Applications of Endophytic Fungi Isolated from Tropical Plants. In: Fungi: Multifaceted Microbes (Ganguli BN and Deshmukh SK, eds.). CRC Press, Anamaya Publishers, Boca Raton 189-207.

CAMPO, R. 2011. Manejo integrado de la antracnosis (Colletotrichum spp.) en ñame (Dioscorea alata), mediante el uso de alternativas para reducir el inoculo primario, la dispersión y el establecimiento del patógeno. 
CUÉLLAR, A.; HUSSEIN, R. 2009. Evaluation of the yield and the antimicrobial activity of the essential oils from: Eucalyptus globulus, Cymbopogon citratus and Rosmarinus officinalis in Mbarara district (Uganda). Revista Colombiana de ciencia animal 1(2): 240- 249.

DANE. 2013. El arroz: producción en Colombia. Boletín mensual insumos y factores asociados a la producción agropecuaria. [Internet] Disponible en: <<http://www.dane.gov.co/files/investigaciones/agropecuario. Fecha de acceso: 18/03/2016

HASSAN, S. M.; HAQ, A. U.; BYRD, J. A.; BERHOW, M. A.; CARTWRIGHT, A. L.; BAILEY, C. A., 2010. Haemolytic and antimicrobial activities of saponin rich extracts from guar meal. Food Chemistry 119: 600-605.

KIM, P.; CHUN, K. 2004. Production of an antifungal protein for control of Colletotrichum lagenarium by Bacillus amyloliquefaciens MET0908. FEMS Microbiology Letters 234(1): 177- 183.

MELNICK, R.; ZIDACK, N.; BAILEY, B.; MAXIMOVA, S.; GUILTINAN, M.; BACKMAN, P. 2008. Bacterial endophytes: Bacillus spp. from annual crops as potential biological control agents of black pod rot of cacao. Biological Control 46:46-56.

PÉREZ, A.; CHAMORRO, L. 2011. Bacterias endófitas: una alternativa biológica para el control de Burkholderia glumae en el cultivo del arroz en Colombia. Revista Colombiana de ciencias Animal 4(1):172-184.

PEREZ, A.; ROJAS, J.; FUENTES, J. 2010. Diversidad de bacterias endófitas asociadas a raíces del pasto colosuana (Bothriochloa pertusa) en tres localidades del departamento de Sucre, Colombia. Acta biológica Colombiana 15(2): 219-228.

PÉREZ, A.; ROJAS, J.; CHAMORRO, L.; PÉREZ, K. 2011. Evaluación in vitro de la actividad inhibitoria de extractos vegetales sobre aislados de Colletotrichum spp. Acta Agronómica 60 (2):158-164.

ROJAS, J.; PÉREZ, A.; MARTínEZ, J.; MIELES, J. 2012. Actividad antibacteriana de extracto de hojas de Melia azedarach L. Revista Colombiana de Biotecnología 14(1): 224- 232.

SIERRA, I.; ROMERO, M.; ORDUZ, S. 2012. Determinación de la actividad antimicrobiana e insecticida de extractos producidos por bacterias aisladas de suelo. Actualidades Biológicas 34 (96): 5-19.

SOUZA, A.; CRUZ, J.; SOUSA, N.; PROCÓPIO, A.; SILVA, G. 2014. Endophytic bacteria from banana cultivars and their antifungal activity. Genetics and Molecular Research 13 (4): 8661-8670.

ZHANYONG, G.; RONGE, X.; SONG, L.; ZHIMEI, Z.; XIA, J.; LIN, W.; PENGCHENG, L. 2008. The Influence of Molecular Weight of Quaternized Chitosan on Antifungal Activity. Journal Carbohydrates and Polymers. 71(4): 694-697.. 